\title{
Reagents for the synthesis of alkenes from carbonyl compounds: applications in the synthesis of terpenoid compounds
}

\author{
William J. Vera, ${ }^{1}$ Manuel S. Laya, ${ }^{1}$ Po S. Poon, ${ }^{1}$ Ajoy K. Banerjee, ${ }^{1 *}$ \\ and Elvia V. Cabrera ${ }^{2}$ \\ ${ }^{1}$ Instituto Venezolano de Investigaciones Científicas (IVIC), Centro de Química, Apartado-21827, \\ Caracas-1020A, Venezuela \\ ${ }^{2}$ Departamento de Química, Facultad Experimental de Ciencias, Universidad del Zulia, \\ Maracaibo, Venezuela \\ Email: aabanerje@gmail.com
}

\begin{abstract}
The carbon-carbon double bond has been introduced by replacing carbonyl group employing various reagents in several decalones and tetralones. The resulting unsaturated compounds have been utilized for the synthesis of natural products related to diterpenes triptolide, taxodione and sesquiterpenes, herbertene, cuauhtemone, warburganal, drim-8-en-7-one, occidol, mansonone F and biflorine.
\end{abstract}

Keywords: Halide, tosylate, mesylate, alkene, dimethylformamide, 2,4-pentanediol

\section{Table of Contents}

1. Introduction

2. Reagents for the Conversion of Carbonyl into Alkene

2.1. Lithium bromide ( $\mathrm{LiBr})$, lithium carbonate $\left(\mathrm{Li}_{2} \mathrm{CO}_{3}\right)$ and dimethylformamide (DMF)

2.2. Thionyl chloride $\left(\mathrm{SOCl}_{2}\right)$, phosphorus oxychloride $\left(\mathrm{POCl}_{3}\right)$ and pyridine

2.3. Acid catalysed ( $p$-toluenesulphonic acid, sulphuric acid, hydrochloric acid) dehydration

2.4. 2,6-Dichloro-3,5-dicyanobenzoquinone (DDQ)

2.5. Grignard reagents $\left(\mathrm{MeMgBr}, \mathrm{Me}_{2} \mathrm{CHMgBr}\right)$

2.6. 2,4-Pentanediol and $p$-toluenesulfonic acid

3. Conclusions

4. Reference 


\section{Introduction}

The formation of carbon-carbon double bond is of fundamental importance in organic synthesis because it allows the introduction of a wide variety of functional groups. As a result, many reactions and reagents have been developed for carbon-carbon double bond formation. Several reagents were utilized by us to obtain alkenes from the carbonyl compounds. The present account is largely a survey of the reagents utilized between 1990-2012 at the Department of Chemistry, IVIC, Caracas and University of Zulia, Maracaibo, Venezuela, for the synthesis of alkenes from carbonyl compounds and their utility in the synthesis of terpenoid compounds.

\section{Reagents for the Conversion of Carbonyl into Alkene}

\subsection{Lithium bromide ( $\mathrm{LiBr})$, lithium carbonate $\left(\mathrm{Li}_{2} \mathrm{CO}_{3}\right)$ and dimethylformamide (DMF)}

The combination of $\mathrm{LiBr}$ and $\mathrm{Li}_{2} \mathrm{CO}_{3}$ in $\mathrm{DMF}$ is a powerful reagent for detosylation to yield alkene. Therefore for the conversion of the ketone into an alkene, a carbonyl group is converted into a tosyl group by reduction and detosylation. The combination of these reagents has been frequently used in our laboratory. Some examples are cited below: Ketoester ${ }^{1} \mathbf{2}$, prepared from the octalin 1, on reduction with sodium borohydride in methanol yielded a mixture of alcohols whose tosyl derivative on heating with $\mathrm{LiBr}, \mathrm{Li}_{2} \mathrm{CO}_{3}$ and DMF afforded the alkene ${ }^{1} \mathbf{3}$ which was converted into the methylene decalone $\mathbf{4}^{2}$ in four steps (bromohydrin reaction, oxidation, dehydrohalogenation, and oxidative decarboxylation).
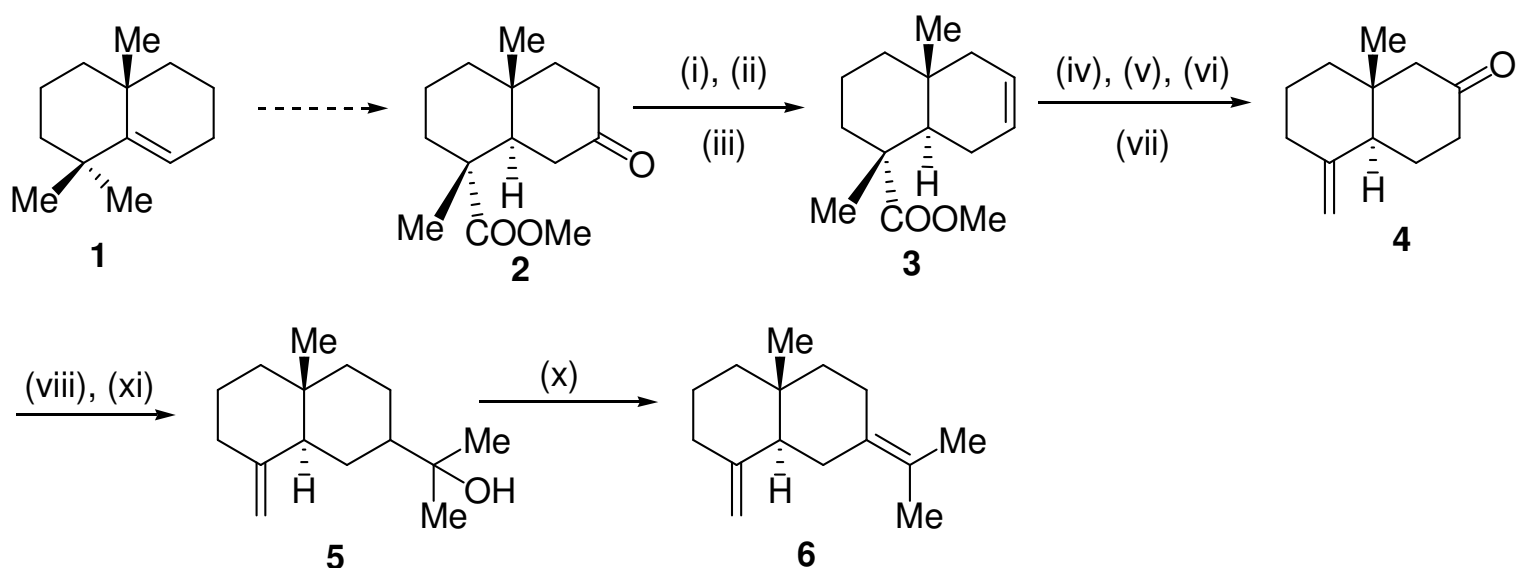

Reagents: (i) $\mathrm{NaBH}_{4}, \mathrm{MeOH}$; (ii) TsCl/Py; (iii) $\mathrm{Li}_{2} \mathrm{CO}_{3}$, $\mathrm{LiBr}$, DMF; (iv) NBS, DMSO; (v) $\mathrm{CrO}_{3}$, $\mathrm{Me}_{2} \mathrm{CO}_{3}$, (vi) collidine, (vii) $\mathrm{Pb}(\mathrm{OAc})_{4}, \mathrm{C}_{6} \mathrm{H}_{6}, \mathrm{Py}$; (viii) $\mathrm{CO}(\mathrm{COOMe})_{2}, \mathrm{DME}, \mathrm{NaH}$; (ix) MeLi, $\mathrm{Et}_{2} \mathrm{O}(2 \mathrm{M}) ;(\mathrm{x}) \mathrm{SOCl}_{2}$, Py

\section{Scheme 1}


Methoxycarbonylation of the decalone $\mathbf{4}$ followed by treatment of the resulting compound with Grignard reagent produced alcohol 5 which on dehydration yielded ${ }^{3}( \pm$ )-eudes-4(14),7(11)-diene-8 6 whose alternative synthesis was already reported. ${ }^{4}$ The synthetic route developed ${ }^{1,3}$ by us is described in Scheme 1. The natural product 6, which was isolated ${ }^{5}$ from Atraclyodes rhizones, exhibits significant anti-inflammatory activity.

The combination of $\mathrm{LiBr}, \mathrm{Li}_{2} \mathrm{CO}_{3}$ in $\mathrm{DMF}$ was also used for the synthesis of alkene 11, a potential intermediate for the synthesis of triptolide $\mathbf{1 2}$ which has abietane skeleton and exhibits cytotoxic activity. The unsaturated ketone ${ }^{6} \mathbf{8}$, obtained by the condensation of the tetralone 7 with 1-chloro-3-pentanone, was converted into the compound $\mathbf{9}$ in three steps (reduction ${ }^{7}$, methylation, isopropylation $^{8}$ ) which on being subjected to demethoxylation, ${ }^{9}$ oxidation and methylation respectively yielded the ketone 10. The conversion of the ketone to the alkene ${ }^{10} \mathbf{1 1}$ in $55 \%$ yield was accomplished by reduction, tosylation and detosylation respectively. The alkene $\mathbf{1 1}$ has already been converted ${ }^{11}$ to triptolide 12 which is a promising anticancer compound. The synthetic route is described in Scheme 2.<smiles>COc1cccc2c1CCC(=O)C2C</smiles>

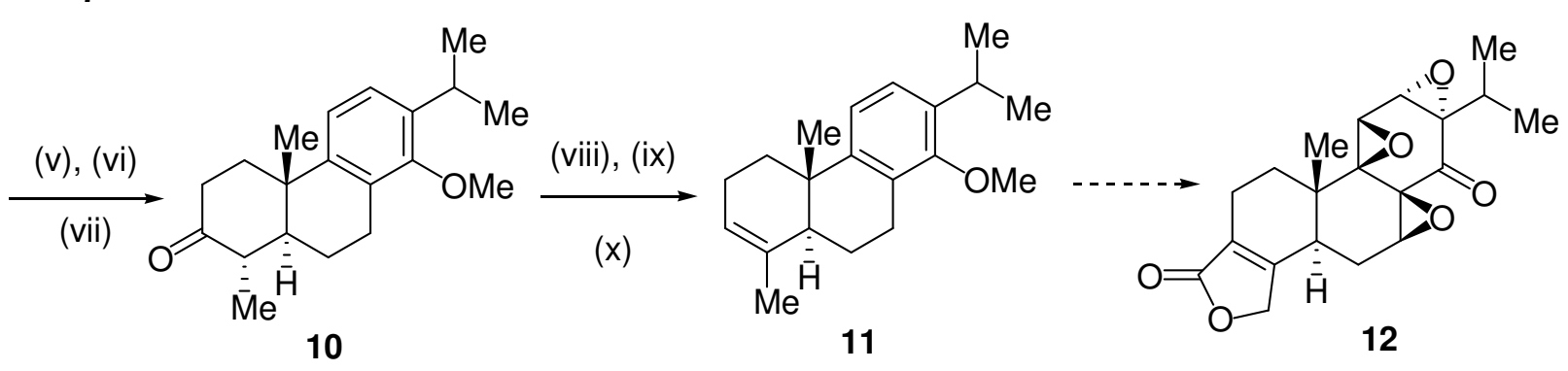

Reagents: (i) 1-chloro-3-pentanone; (ii) $\mathrm{Na}, n$-propanal; (iii) Mel, NaH, THF; (iv) isopropanal, PPA; (v) MeSiCl, Nal, MeCN; (vi) $\mathrm{CrO}_{3}, \mathrm{H}_{2} \mathrm{SO}_{4}$; (vii) $\mathrm{Me}_{2} \mathrm{SO}_{4}, \mathrm{~K}_{2} \mathrm{CO}_{3}, \mathrm{Me}_{2} \mathrm{CO}$; (viii) $\mathrm{NaBH}_{4}, \mathrm{MeOH}$; (ix) TsCl/ Py; (x) $\mathrm{Li}_{2} \mathrm{CO}_{3}$, DMF

\section{Scheme 2}

The use of $\mathrm{LiBr}, \mathrm{Li}_{2} \mathrm{CO}_{3}$ and DMF in detosylation for the synthesis of alkene has also been observed during our realization of the synthesis $^{1}$ of sesquiterpene $( \pm)$-herbertene 17, which possesses a 1,1,2-trimethyl-2-m-tolycyclopentane structure. The known ${ }^{12}$ ketone $\mathbf{1 3}$ on methylation afforded the methylated ketone 14 (Scheme 3) whose transformation to the diene 15 was accomplished by reduction, tosylation and detosylation respectively. The $\alpha, \beta$-unsaturated ketone obtained by oxidation of the diene $\mathbf{1 5}$ on cyanation and reduction respectively yielded an aldehyde 
which was further reduced ${ }^{13}$ to obtain the alcohol 16. Frater ${ }^{14}$ observed that the alcohol 16 on treatment with perchloric acid underwent transformation yielding the aromatic sesquiterpene herbertene 17. Thus an alternative route ${ }^{15}$ of the alcohol 16 prepared from the diene 15 constitutes a potential intermediate for the natural product $( \pm)$-herbertene 17.<smiles>CC1(C)CCCC2CCC(=O)C=C21</smiles>

13

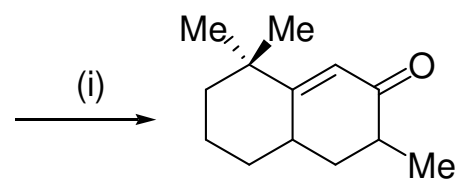

14

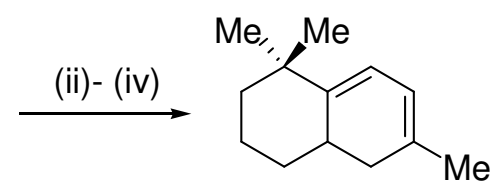

15

(v) - (viii)<smiles>CC1=CC=C2C(CCCC2(C)C)C1CO</smiles>

16

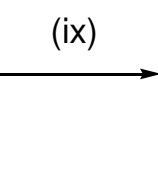

(ix)

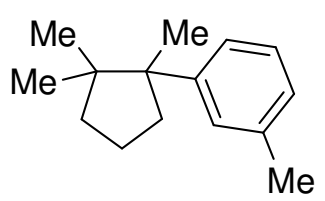

17

Reagents: (i) LDA, HMPA,Mel, $-70^{\circ} \mathrm{C}$; (ii) $\mathrm{NaBH}_{4}, \mathrm{MeOH}$;(iii) $\mathrm{TsCl} / \mathrm{Py}$; (iv) $\mathrm{LiBr}$, $\mathrm{Li}_{2} \mathrm{CO}_{3}$, DMF; (v) $\mathrm{CrO}_{3}, \mathrm{Py}$; (vi) $\mathrm{C}_{4} \mathrm{H}_{9} \mathrm{OK}, \mathrm{t}-\mathrm{BuOH}$, Tosmic, DMF; (vii) DIBAL, Toluene; (viii) $\mathrm{NaBH}_{4}$ - Alox complex; (ix) $\mathrm{HClO}_{4}$

\section{Scheme 3}

The combination of $\mathrm{LiBr}, \mathrm{Li}_{2} \mathrm{CO}_{3}$ and $\mathrm{DMF}$ has also been utilized for dehydro-bromination to

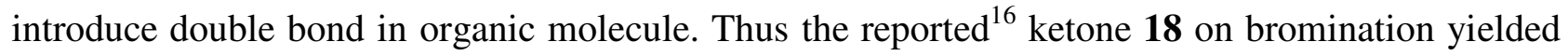
bromoketone which on dehydrobromination with $\mathrm{LiBr}, \mathrm{Li}_{2} \mathrm{CO}_{3}$ and $\mathrm{DMF}$ afforded unsaturated ketone $^{17} 19$ whose conversion to the olefin ester 20 was accomplished without any difficulty using standard organic reactions. The unsaturated ester may serve as a potential intermediate for the synthesis of the racemic occidentalol 21 (Scheme 4), a eudesmane-type sesquiterpene, isolated from the wood of Eastern white cedar (Thuja occidentalis L.) and characterized by the presence of cis-fused decalin system and a homo annular 1,3-diene unit in the molecule. ${ }^{18}$ 
<smiles>COC1CC[C@]2(C)C(=O)CCC[C@H]2C1C</smiles>

18<smiles>[M]C12CCC(OC)C(C)C1CC=CC2=O</smiles>

19<smiles>COC(=O)C1C=CC2(C)CCC(OC)C(C)C2C1</smiles>

20

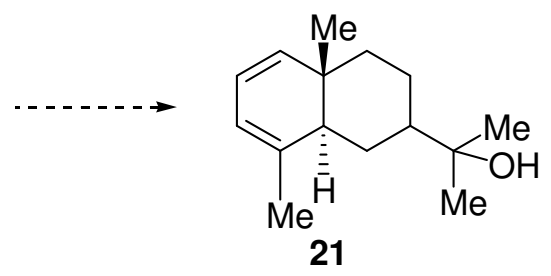

Reagents: (i) $\mathrm{C}_{5} \mathrm{H}_{6} \mathrm{NBr}_{3}$, $\mathrm{EtOH}, \mathrm{CHCl}_{3}$; (ii) $\mathrm{LiBr}, \mathrm{Li}_{2} \mathrm{CO}_{3}$, DMF

\section{Scheme 4}

During the synthesis ${ }^{19}$ of the drimane sesquiterpene drim-8-en-7-one (Scheme 5) the utility of the reagent $\mathrm{LiBr}, \mathrm{Li}_{2} \mathrm{CO}_{3}$ and $\mathrm{DMF}$ in dehydrohalogenation has also been noted. The already reported $^{20}$ alcohol 22 was converted to the ketone $\mathbf{2 3}$ in three steps (dehydration, oxidation and conjugate methylation). Its conversion to the ketone $\mathbf{2 4}$ was realized by ethoxycarbonylation, methylation and decarboxylation respectively. Bromination of $\mathbf{2 4}$ followed by dehydrobromination with $\mathrm{LiBr}, \mathrm{Li}_{2} \mathrm{CO}_{3}$ and DMF proved useful in the introduction of double bond at the C-8 and C-9 of the compound 24 yielding drim-8-en-7-one 25 in good yield which is a sesquiterpene and previously synthesized from drimenol. ${ }^{21}$

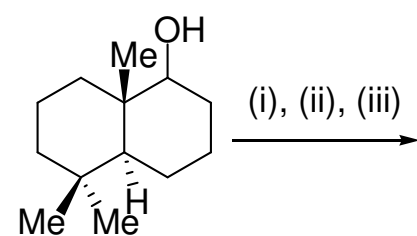

22<smiles>CC1CC(=O)CC2C(C)(C)CCCC12C</smiles>

23

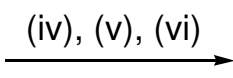<smiles>CC1CCCC2(C)C(C)C(C)C(=O)CC12</smiles>

24

(vii), (viii)<smiles>CC1=C(C)[C@]2(C)CCCC(C)(C)[C@@H]2CC1=O</smiles>

25

Reagents: (i) PTSA on silica gel, $\mathrm{CHCl}_{3}$; (ii) $\mathrm{CrO}_{3}$, 3,5-DMP; (iii) $\mathrm{MeLiCu}_{2}$; (iv) $\mathrm{CO}(\mathrm{COOEt})_{2}$, $\mathrm{NaH}$, DME; (v) DMF, NaH, Mel, MeCOOH; (vi) DMSO, LiCl, $\mathrm{H}_{2} \mathrm{O}, 170$ - $180^{\circ} \mathrm{C}$; (vii) $\mathrm{Br}_{2}$, $\mathrm{CHCl}_{3}, \mathrm{MeCOOH}$; (viii) $\mathrm{LiBr}, \mathrm{Li}_{2} \mathrm{CO}_{3}$, DMF

\section{Scheme 5}


Thus it can be seen that the combination of the $\mathrm{LiBr}, \mathrm{Li}_{2} \mathrm{CO}_{3}$ and $\mathrm{DMF}$ is an important reagent for detosylation and dehydrobromination thus for the introduction of double bond in a suitable position of organic molecule yielding the alkenes 3, 11, 15, 19 and 25 which have been utilized for the synthesis of potential intermediate for natural products related to sesquiterpenes and diterpenes.

\subsection{Thionyl chloride $\left(\mathrm{SOCl}_{2}\right)$, phosphorus oxychloride $\left(\mathrm{POCl}_{3}\right)$ and pyridine}

Thionyl chloride and pyridine have been extensively used for dehydration of alcohols ${ }^{22,23}$ which undergo molecular transformation with this reagent yielding substituted alkenes and many unexpected products. Darzens ${ }^{23}$ has reported the formation of olefin ester 27 by the dehydration of tertiary alcohol 26 with thionyl chloride and pyridine. The introduction of double bond at the adjacent position of the carbonyl group of the alcohol 28 was achieved ${ }^{24}$ by dehydration with thionyl chloride and pyridine but Apsimon and Yamasaky ${ }^{25}$ encountered difficulty in the dehydration of tertiary alcohol $\mathbf{3 0}$ to the alkene $\mathbf{3 1}$ (Scheme 6) employing the mentioned reagent.

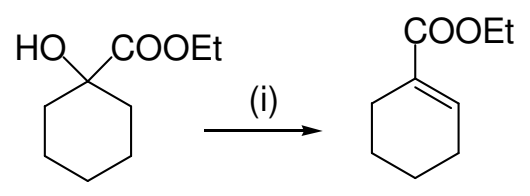

26

27

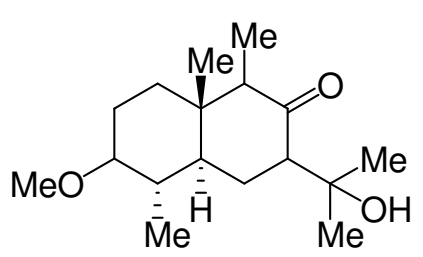

28

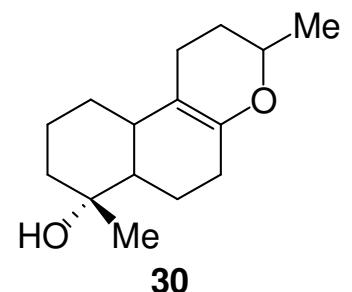

30

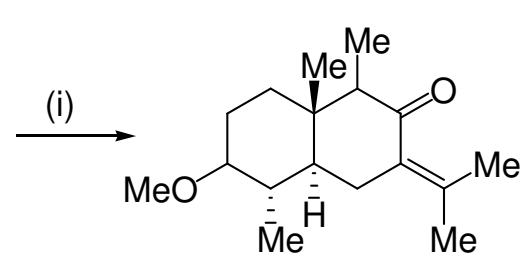

29

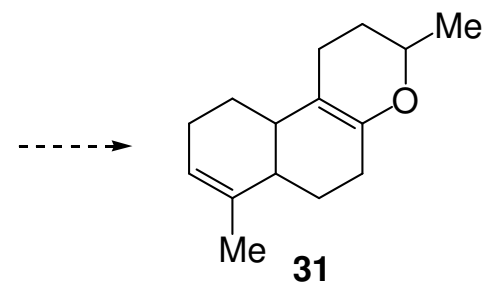

Reagents: (i) $\mathrm{SOCl}_{2}$, Py

\section{Scheme 6}

A spectacular rearrangement of the tertiary alcohol ${ }^{26} \mathbf{3 2}$ to the tetrasubstituted alkene $\mathbf{3 3}$ was observed by the treatment with thionyl chloride and pyridine (Scheme 7). The transformation can be explained by assuming the formation of an intermediate $\mathbf{A}$ from which the elimination of the chlorosulfite group (OSOCl) and 1,2-methyl-group shift occurred in a concerted manner leading to the formation of cyclic alkene 33. Similar observation ${ }^{26}$ was also recorded by isolation of the alkene 35 during the dehydration of tertiary alcohol 34 with thionyl chloride and pyridine. We believe that the alkene $\mathbf{3 5}$ can be utilized for the synthesis of sesquiterpenoid compounds. 


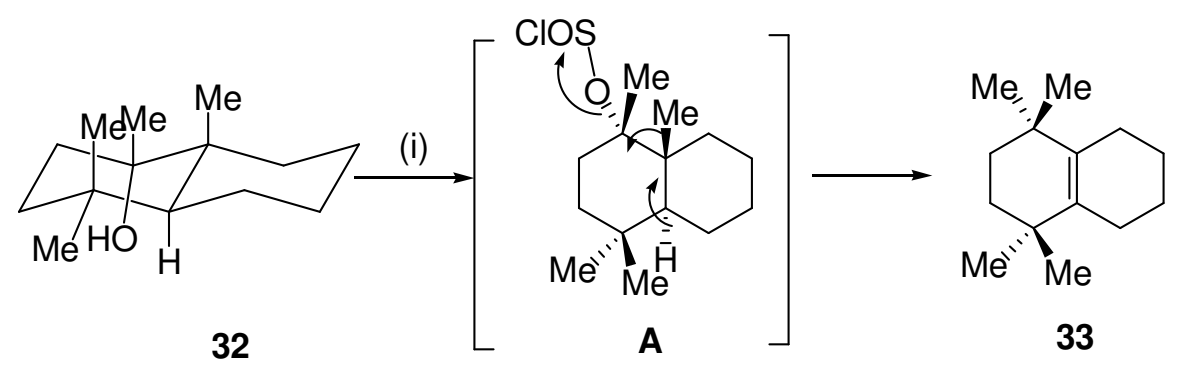

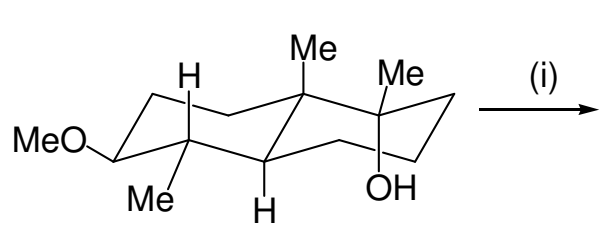

34<smiles>COC1CCC2=C(CCCC2(C)C)C1C</smiles>

35

Reagents: (i) $\mathrm{SOCl}_{2}$, Py

\section{Scheme 7}

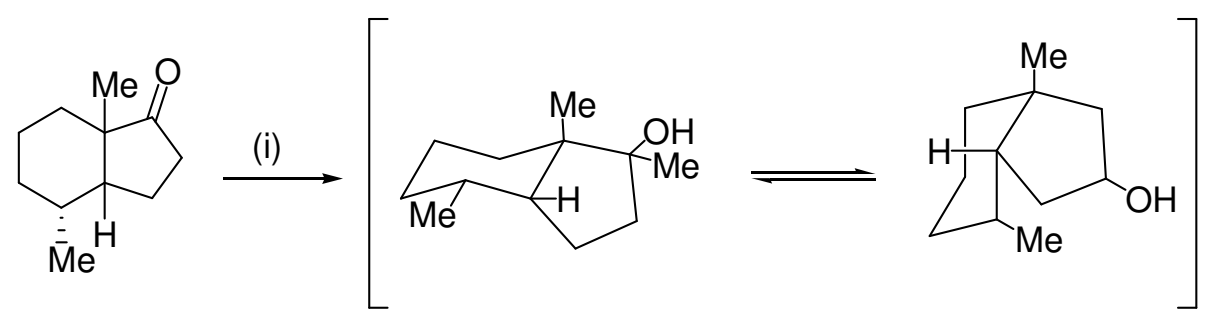

36

37

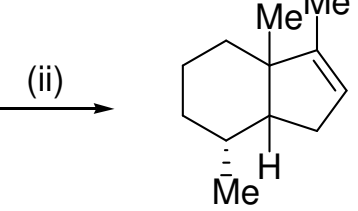

38

\section{Scheme 8}

Reagents: (i) $\mathrm{MeLi}, \mathrm{Et}_{2} \mathrm{O}$; (ii) $\mathrm{SOCl}_{2}, \mathrm{Py}$

A very interesting observation was recorded ${ }^{26}$ during the dehydration of octahydroindenol 37, prepared from the ketone ${ }^{26} \mathbf{3 6}$. The alcohol 37 on treatment with thionyl chloride and pyridine suffered no rearrangement like the other tertiary alcohols $\mathbf{3 2}$ and $\mathbf{3 4}$ but afforded only the alkene $\mathbf{3 8}$ (Scheme 8) in major amount. It was very curious to find that the alcohols $\mathbf{3 2}$ and $\mathbf{3 4}$ underwent rearrangement with thionyl chloride and pyridine while under similar reaction condition alcohol 37 produced the alkene 38. We believe that the trans-juncture of the alcohols $\mathbf{3 2}$ and $\mathbf{3 4}$ enable an 
antiplanar arrangement of the migrating methyl group and the hydrogen at the bridgehead position, thus fulfilling the stereoelectronic requirement for a more or less synchronous eliminationrearrangement reaction. A similar orientation can not be adopted by the alcohol $\mathbf{3 7}$.

The mentioned examples indicate that the thionyl chloride has played an important role in the dehydration of alcohols, thus affording the alkenes 27, 29, 33, 35 and $\mathbf{3 8}$. We believe that these alkenes can be utilized as starting material for the synthesis natural products and bioactive substances.

\subsection{Acid catalysed ( $p$-toluenesulphonic acid, sulphuric acid, hydrochloric acid) dehydration} Dehydration of alcohols catalyzed by acid especially by $p$-toluenesulphonic acid has frequently been used in our laboratory for the synthesis of alkenes. It is necessary to mention that dehydration of alcohols with $p$-toluenesulphonic acid, sulphuric acid and hydrochloric acid most often yield the desired alkene. In some occasions occurs the rearrangement of molecule. During the synthesis of terpenoid compounds the introduction of olefinic bond in the suitable position was essential. The acid catalyzed dehydration proved useful to achieve the objective. Some examples are cited below.

The ketone ${ }^{27} 39$ was treated with diethyl carbonate and sodium hydride in dimethoxyethane to yield $\beta$-ketoester $\mathbf{4 0}$ which was made to react with $\mathrm{MeLi}$ in ether to obtain the tertiary alcohol. Dehydration with 10\% hydrochloric acid yielded the alkenes $\mathbf{4 1}$ and $\mathbf{4 2}$ in unequal proportion. The dehydration with thionyl chloride and phosphorous oxychloride was not successful. The formation of these alkenes proved useful for the synthesis of the sesquiterpenes junenol $\mathbf{4 4}$ and acalomone $\mathbf{4 5}$ because direct introduction of the isopropyl group to the ketone $\mathbf{3 9}$ was not successful. Hydrogenation of the mixture of these alkenes generated the isopropyl ketone $\mathbf{4 3}$ which was utilized $^{28}$ for the synthesis of sesquiterpenes junenol $\mathbf{4 4}$ and acolamone $\mathbf{4 5}$ (Scheme 9).

Dehydration of alcohol catalyzed by acid to obtain alkene was also attempted during the synthesis of ( \pm )-taxodione $\mathbf{5 1}$ which is a diterpenoid quinone and exhibits its tumor inhibitory activity against Walker carcino sarcoma 256 in rats.

Ketone $^{29} 46$ was converted to the alcohol 47 by treatment with acetone and lithium diisopropylamide in tetrahydrouran. Heating the alcohol $\mathbf{4 7}$ in benzene under reflux with a catalytic amount of $p$-toluenesulfonic acid produced the dienone 48 (Scheme 10). Due to the formation of the dienone 48, the synthesis of taxodione 51 was achieved without any difficulty. The dienone $\mathbf{4 8}$ on heating with 5\% sulphuric acid in methanol underwent aromatization yielding phenol which on methoxylation produced the dimethoxy compound 49. Demethoxylation followed by oxidation and methoxylation afforded the tricyclic ketone $\mathbf{5 0}$ whose transformation to taxodione $\mathbf{5 1}$ has already been reported. ${ }^{30}$ 

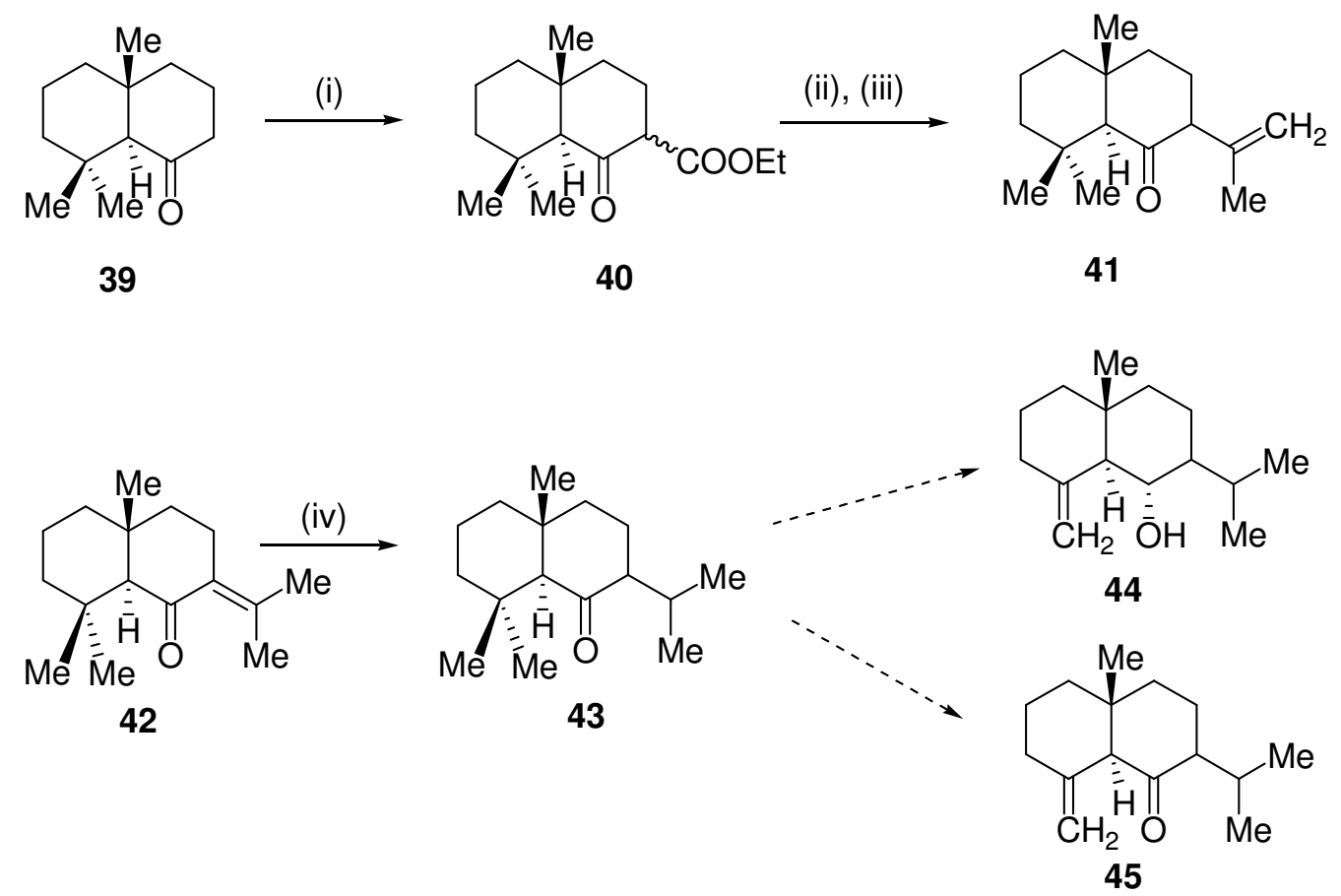

Reagents: (i) $\mathrm{CO}(\mathrm{COOEt})_{2}, \mathrm{NaH}$; (ii) $\mathrm{MeLi} \mathrm{Et}_{2} \mathrm{O}$; (iii) $10 \% \mathrm{HCl}, \mathrm{MeOH}$; (iv) $\mathrm{PtO}_{2}, \mathrm{MeOH}$

\section{Scheme 9}

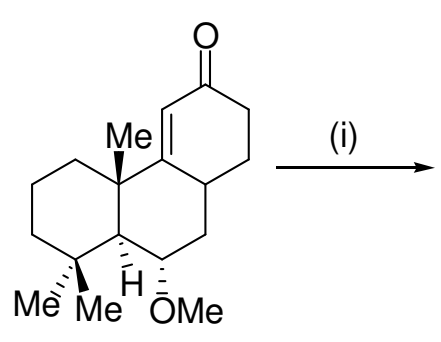

46<smiles>CO[C@H]1C[C@@H]2CC(C(C)(C)O)C(=O)C=C2[C@@]2(C)CCC[C@H](C)[C@H]12</smiles>

47<smiles>CO[C@H]1C[C@@H]2CC(=C(C)C)C(=O)C=C2[C@@]2(C)CCC[C@H](C)[C@H]12</smiles>

48<smiles>COc1cc2c(cc1C(C)C)C[C@H](OC)C1C(C)[C@H](C)CC[C@@]21C</smiles>

Reagents: (i) LDA, $\mathrm{ZnCl}_{2}, \mathrm{Me}_{2} \mathrm{CO}$; (ii) PTSA, $\mathrm{C}_{6} \mathrm{H}_{6}$; (iii) $5 \% \mathrm{H}_{2} \mathrm{SO}_{4}, \mathrm{MeOH}$; (iv) $\mathrm{Me}_{2} \mathrm{SO}_{4}$, $\mathrm{Me}_{2} \mathrm{CO}, \mathrm{K}_{2} \mathrm{CO}_{3}$; (v) $\mathrm{Me}_{3} \mathrm{SiCl}$, Nal, MeCN: (vi) $\mathrm{CrO}_{3}, \mathrm{H}_{2} \mathrm{SO}_{4}$

\section{Scheme 10}


The utility of $p$-toluenesufonic acid in the synthesis of alkene has been recorded ${ }^{31}$ during the synthesis of 8-methylene-4,4,8a-trimethyl-7-oxo-octahydronaphthalene 57 (Scheme 11). The alcohol $^{1} \mathbf{5 2}$ on dehydration with $p$-toluenesulfonic acid adsorbed on silica gel afforded the alkene $\mathbf{5 3}$ in $97 \%$ yield. The double bond occupied the desired position and thus the synthesis of $\mathbf{5 7}$ was accomplished without difficulty. The alkene $\mathbf{5 3}$ was converted to olefin ester $\mathbf{5 4}$ in two steps (allylic oxidation and carboxylation). The catalytic hydrogenation and metal hydride reduction the produced the diol 55. Selective oxidation with hypochlorite in acetic acid afforded the diol 56 whose tosyl derivative underwent smooth elimination on treatment with base furnishing the desired compound 57, a potential intermediate for the synthesis of terpenoid compounds such as zonarol, isozonarol, 2-desoxystemodinone and the perfumery agent (+)-ambrox.
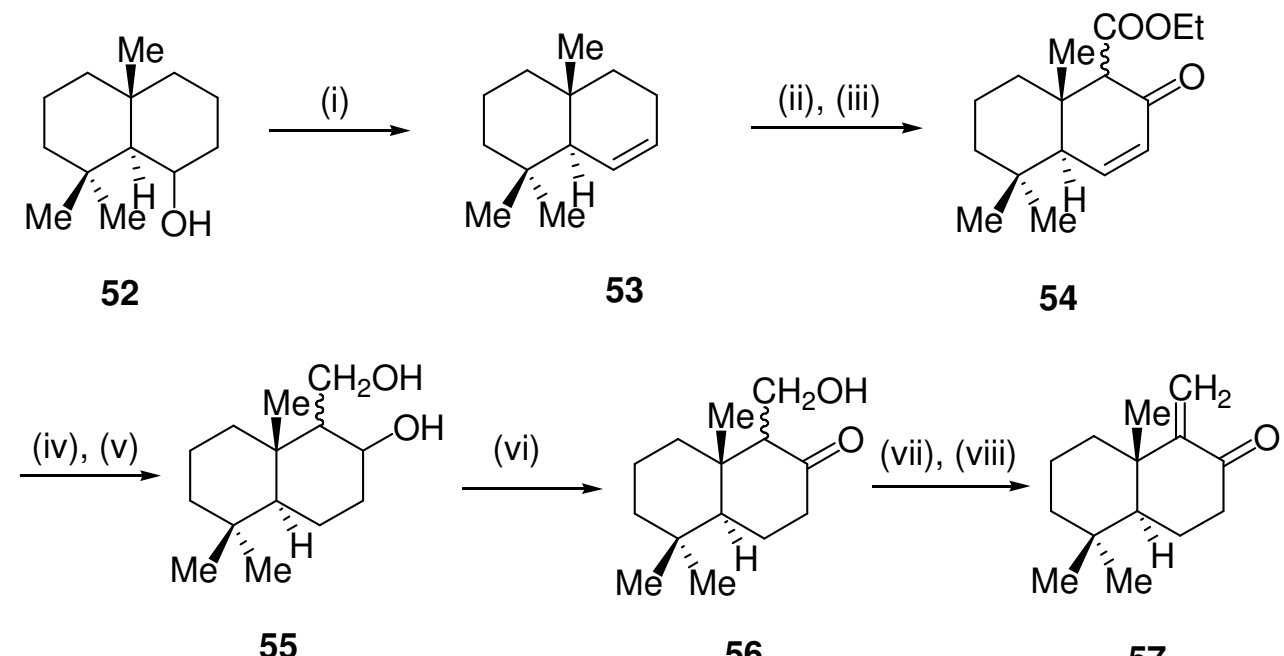

Reagents: (i) PTSA, silica gel; (ii) $\mathrm{CrO}_{3}$, Py, 3,5dimethylpyrazole; (iii) DME, $\mathrm{CO}(\mathrm{COOEt})_{2}$, $\mathrm{NaH}$; (iv) $\mathrm{PtO}_{2}, \mathrm{MeOH}$; (v) $\mathrm{LiAlH}_{4}, \mathrm{THF}$; (vi) $\mathrm{NaClO}_{4}, \mathrm{MeCOOH}$, (vii) TsCl, Py; (viii) 1,5diazabicyclo[5.4.0]-undec-5-ene

\section{Scheme 11}

The examples cited above exhibit the role of acids in conversion of the alcohols into the alkenes 41, 42, 48 and 53 which were utilized in the synthesis of potential intermediates for diterpene and sesquiterpene.

\subsection{2,6-Dichloro-3,5-dicyanobenzoquinone (DDQ)}

2,6-dichloro-3,5-dicyanobenzoquinone (DDQ) has been employed in our laboratory for the introduction of double bond adjacent to carbonyl group. It can be seen from the examples cited below that the facile introduction of the double bond adjacent to carbonyl group was very helpful in the synthesis of decalin and phenanthrene moiety for their conversion to natural products. Some examples are given below. 
Ketone 58 on heating with DDQ in dioxane yielded the dienone $\mathbf{5 9}$ whose transformation to the tetralin 60 was achieved by metal hydride reduction followed by treatment with thionyl chloride and pyridine. The resulting product on further reduction followed by oxidation produced the ketone $^{32} \mathbf{6 1}$ which is a potential intermediate for the synthesis ${ }^{33}$ of sesquiterpene platphyllide $\mathbf{6 2}$ (Scheme 12). The transformation of 59 can be explained by assuming the formation of the intermediate A whose methyl group migrated followed by the elimination of the chlorosulfite (OSOCl) leading to the formation of the intermediate $\mathbf{B}$ which rearranged to the tetralin $\mathbf{6 0}$.

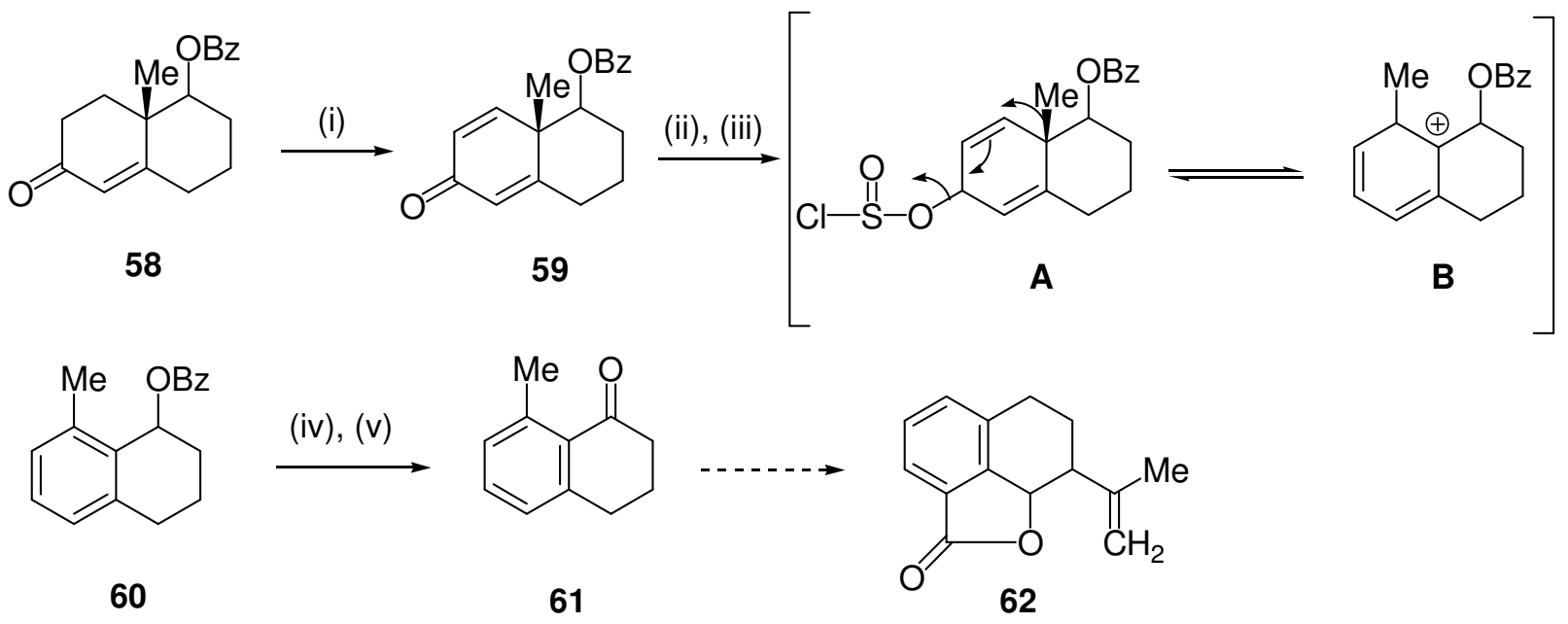

Reagents: (i) DDQ, dioxane; (ii) $\mathrm{NaBH}_{4}, \mathrm{MeOH}$; (iii) $\mathrm{SOCl}_{2}$, Py; (iv) $\mathrm{LiAlH}_{4}$, THF; (v) $\mathrm{BaMnO}_{4}, \mathrm{CH}_{2} \mathrm{Cl}_{2}$

\section{Scheme 12}

Similarly the ketone ${ }^{34} 63$ in dioxane on heating with DDQ yielded the dienone ${ }^{35} 64$ which was converted to phenol 65 by heating with acid. The phenol was utilized for the synthesis of phytoalexin orchinol $^{36} \mathbf{6 6}$, a dihydrophenanthrene and biological active natural product (Scheme 13).

Finally it is worthwhile to add another example to show the use of DDQ in dehydrogenation of organic compounds. The ketoesters ${ }^{37} 67$ was converted to the dienone 68 by heating with DDQ in dioxane. The dienone were subjected to hydrolysis with potassium $t$-butoxide in $t$-butanol. Decarboxylation followed by aromatization occurred in one step yielding the tetralol 69 which was methylated and oxidized to obtain the tetralone 70. Methylation ${ }^{38}$ of the tetralone $\mathbf{7 0}$ furnished the tetralone $^{37} \mathbf{7 1}$ in good yield (Scheme 14). The tetralone $\mathbf{7 0}$ is an useful intermediate ${ }^{39}$ for the construction of the fundamental skeleton of steroids and the tetralone $\mathbf{7 1}$ has been utilized for the synthesis ${ }^{40}$ of cloven-3-one and epiclovene-3-one. 
<smiles>COc1ccc2c(c1)CCc1cc(O)cc(C)c1-2</smiles>

63
65<smiles>COc1cc(C)c2c(c1)CCc1cc(O)ccc1-2</smiles>

Reagents: (i) DDQ, dioxane; (ii) PTSA, $\mathrm{C}_{6} \mathrm{H}_{6}$

\section{Scheme 13}<smiles>CC1=C2CCCC(C(=O)O)(CCC2=O)C1</smiles>

67

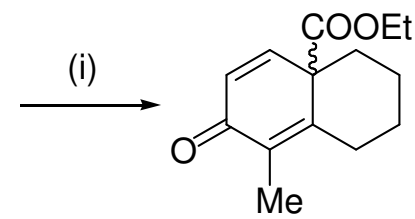

68<smiles>Cc1c(O)ccc2c1CCCC2</smiles>

69<smiles>COc1ccc2c(c1C)CCC(C)C2=O</smiles>

Reagents: (i) DDQ, dioxane; (ii) $\mathrm{C}_{4} \mathrm{H}_{9} \mathrm{OK} / \mathrm{C}_{4} \mathrm{H}_{9} \mathrm{OH}$; (iii) $\mathrm{Me}_{2} \mathrm{SO}_{4}, \mathrm{Me}_{2} \mathrm{CO}$; (iv) $\mathrm{CrO}_{3}$, $\mathrm{MeCOOH}$; (v) $\mathrm{Et}_{3} \mathrm{~B}, \mathrm{NaH}$, Mel

\section{Scheme 14}

It can easily be appreciated the use of DDQ in the conversion of $\alpha, \beta$-unsaturated ketones into the dienones and their utility in the synthesis of terpenoid compounds.

\subsection{Grignard Reagents (MeMgBr, $\mathrm{Me}_{2} \mathrm{CHMgBr}$ )}

The chemical literature indicates that many Grignard reagents have been used the direct conversion of the carbonyl group into the alkene for their transformations into potential intermediates for the synthesis of natural products and bioactive compounds. In relation of our studies on terpenoid compounds several tetralones were made to react with Grignard reagents to yield alkenes and most 
of these alkenes were utilized either for the synthesis of diterpenes and sesquiterpenes or potential intermediates for the terpenoid compounds. Some examples are cited below.

7-methoxy-1-tetralone $\mathbf{7 2}$ was made to react with isopropylmagnesium chloride in ether in presence of cerium chloride to obtain an alcohol, which on dehydration with $p$-toluenesulphonic acid yielded the alkene ${ }^{41} \mathbf{7 3}$ in high yields whose transformation into the tetralone $\mathbf{7 4}$ was accomplished by hydrogenation and oxidation respectively. Tetralone $\mathbf{7 4}$ is a potential intermediate for the sesquiterpene $( \pm$ )-cadinene dihydrochloride 75 (Scheme 15).<smiles>COc1ccc2c(c1)C(=O)CCC2</smiles>

72

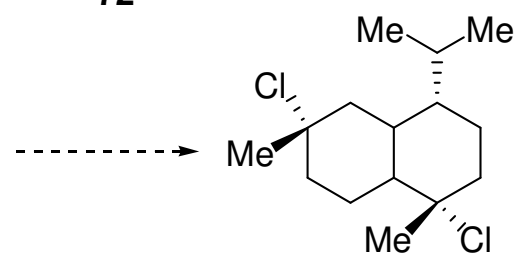

73

74

75

Reagents: (i) i-PrMgCl, $\mathrm{CeCl}_{3}$, THF, $0{ }^{\circ} \mathrm{C}$; (ii) PTSA, $\mathrm{C}_{6} \mathrm{H}_{6}$; (iii) $\mathrm{H}_{2}, \mathrm{Pd}-\mathrm{C} 10 \%, 1$ atm;

(iv) $10 \% \mathrm{CrO}_{3}-\mathrm{AcOH}$

\section{Scheme 15}

Similarly the tetralone 76, on treatment with isopropylmagnesium chloride in presence of cerium chloride followed by dehydration produced the alkene $\mathbf{7 7}$ which on dihydrogenation afforded the substituted naphthalene 78. The conversion of $\mathbf{7 8}$ into the phenolic sesquiterpene $( \pm)$ cis-5-hydroxycalamenene $\mathbf{7 9}$ was realized $^{42}$ in three steps (demethoxylation, formylation and hydrogenation) (Scheme 16). The sesquitepene 79 possess antioxidant, antimicrobial and antifungal activity. 
<smiles>C#CC1CCC(=O)c2c(OC)cccc21</smiles>

76<smiles>Cc1ccc2c(c1O)C(C(C)C)CCC2C</smiles><smiles>COc1cccc2c1C(C(C)C)=CCC2C</smiles>

77<smiles>COc1cccc2cccc(C(C)C)c12</smiles>

78

79

Reagents: (i) i-PrMgCl, THF, $0{ }^{\circ} \mathrm{C}$; (ii) $\mathrm{HCl}, 6 \mathrm{~N}$; (iii) $\mathrm{DDQ}, \mathrm{CH}_{2} \mathrm{Cl}_{2}$

\section{Scheme 16}

5-Methoxy-1-tetralone 80 was converted to the alkene $\mathbf{8 1}$ by the mentioned procedure. The alkene $\mathbf{8 1}$ was subjected to hydrogenation, bromination, metalation and methylation respectively to obtain the methyltetralin 82. Its conversion to the tetraol 83 (Scheme 17) was accomplished in three steps (bromination, formylation and oxidative rearrangement). ${ }^{43}$ The three steps conversion of tetraol into the sesquiterpene $( \pm)$-cacalol 84 has already been accomplished ${ }^{44}$ employing standard organic reactions. Thus the alkene $\mathbf{8 1}$ can be considered as potential intermediate for the synthesis de cacalol 84 whose biological activities are well documented. ${ }^{44}$<smiles>COc1cccc2c1CCCC2=O</smiles>

80

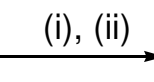

(iv), (vi), (vii)<smiles>COc1cccc2c1CCC=C2C</smiles>

81 (iii), (iv), (v)<smiles>COc1ccc(C)c2c1CCCC2C</smiles>

82<smiles>COc1c(O)cc(C)c2c1CC[C](C)C2C</smiles>

83<smiles>Cc1coc2c(O)c3c(c(C)c12)C(C)CCC3</smiles>

84

Reagents: (i) $\mathrm{MeMgBr}, \mathrm{Et}_{2} \mathrm{O}$; (ii) $\mathrm{HCl}, 6 \mathrm{~N}$; (iii) $\mathrm{H}_{2}, \mathrm{Pd} / \mathrm{C}, \mathrm{EtOH}$; (iv) $\mathrm{NH}_{4} \mathrm{Br}, \mathrm{H}_{2} \mathrm{O}_{2}$, $\mathrm{AcOH}$; (v) n-BuLi, Mel; (vi) DMF, n-BuLi; (vii) $\mathrm{H}_{2} \mathrm{O}_{2}, \mathrm{H}_{2} \mathrm{SO}_{4}, \mathrm{MeOH}$

\section{Scheme 17}


6-Methoxy-1-tetralone 85 was converted by the mentioned Grignard reagent to the alkene 86. Its conversion into the tetralone $\mathbf{8 7}$ was effected by catalytic hydrogenation and oxidation respectively. Tetralone $\mathbf{8 7}$ served as potential intermediate for the synthesis ${ }^{45}$ of cadalen-15-oic acid $\mathbf{8 8}$ (Scheme 18), a sesquiterpene that exhibits anti-inflamatory and analgesic activity.<smiles>COc1ccc2c(c1)CCCC2=O</smiles>

$\stackrel{\text { (i), (ii) }}{\longrightarrow}$

85<smiles>COc1ccc2c(c1)CCC=C2C</smiles>

86

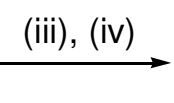<smiles>COc1ccc2c(c1)C(=O)CCC2C</smiles>

87

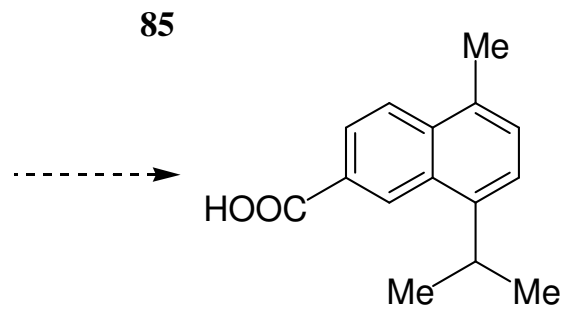

88

Reagents: (i) $\mathrm{MeMgBr}$; (ii) $\mathrm{HCl}, 6 \mathrm{~N}$; (iii) $\mathrm{H}_{2}, \mathrm{Pd} / \mathrm{C}\left(10 \%\right.$ ); (iv) $10 \% \mathrm{CrO}_{3}-\mathrm{CH}_{3} \mathrm{CO}_{2} \mathrm{H}$

\section{Scheme 18}

The importance of Grignard reagents in the synthesis of the alkenes $\mathbf{7 3 , 7 7 , 8 1}$ and $\mathbf{8 6}$, from the tetralones can be observed from the mentioned examples. These alkenes proved useful for the synthesis of bioactive sesquiterpenes.

\subsection{2,4-Pentanediol and $p$-toluenesulfonic acid}

It was reported by Vuligonda and collaborators ${ }^{46}$ that 1-tetralones on heating with 2,4-pentanediol and $p$-toluenesulfonic acid are converted to dihydronaphthalenes. We have observed this method worked successfully with some substituted 1-tetralones, prepared in our laboratory. The dihydronaphthalenes were obtained in high yield. Thus the tetralones 89-91 were converted to dihydronaphthalenes ${ }^{47-49}$ 92-94 respectively in good yield (Scheme 19). These naphthalenes on epoxidation and acid hydrolysis afforded tetralones 95-97 respectively.

The tetralone 95 is an attractive intermediate for the synthesis of occidol ${ }^{50}$ and emmotin-G methyl ether ${ }^{51}$. Tetralone 96 has been used as starting material for many dopaminergic compounds. Its utility has been recorded in the synthesis of natural alkaloids, cyclic amino acids and as novel antagonists of human TRPVT. The tetralone $\mathbf{9 7}$ is an intermediate in the synthesis of analgesics, morphines and steroids. These tetralones were obtained very easily and in high yield due to one step deoxygenation procedure with 2,4-pentanediol and $p$-toluenesulphonic acid. 
<smiles>Cc1ccc(C)c2c1CCCC2=O</smiles>

(i), (ii)<smiles>Cc1ccc(C)c2c1C=CCC2</smiles>

92<smiles>Cc1ccc(C)c2c1CCC(=O)C2</smiles>

95<smiles>COc1cc2c(cc1OC)C(=O)CCC2</smiles>

90<smiles></smiles><smiles>COc1cc2c(cc1OC)CCC=C2</smiles>

93<smiles>COc1cc2c(cc1OC)CC(=O)CC2</smiles>

96<smiles>COc1ccc2c(c1OC)C(=O)CCC2</smiles>

91

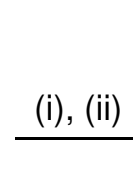<smiles>COc1ccc2c(c1OC)C=CCC2</smiles>

94<smiles>CCc1c(OC)ccc2c1CC(=O)CC2</smiles>

97

Reagents: (i) 2,4-pentanediol; (ii) PTSA, Toluene, reflux; (iii) MCPBA, $\mathrm{CH}_{2} \mathrm{Cl}_{2}$; (iv) $\mathrm{H}_{2} \mathrm{SO}_{4}$ dil, EtOH, reflux

\section{Scheme 19}

A possible mechanism for the formation of the alkene from tetralone is depicted in Scheme 20. The $p$-toluenesulphonic acid forms the carbocation 99 from the tetralone $\mathbf{9 8}$. The carbocation 99 is converted to the benzylic alcohol 100 due to the migration of the hydride anion from the 2,4pentanediol. The alcohol 100 undergoes dehydration to the alkene $\mathbf{1 0 1}$.
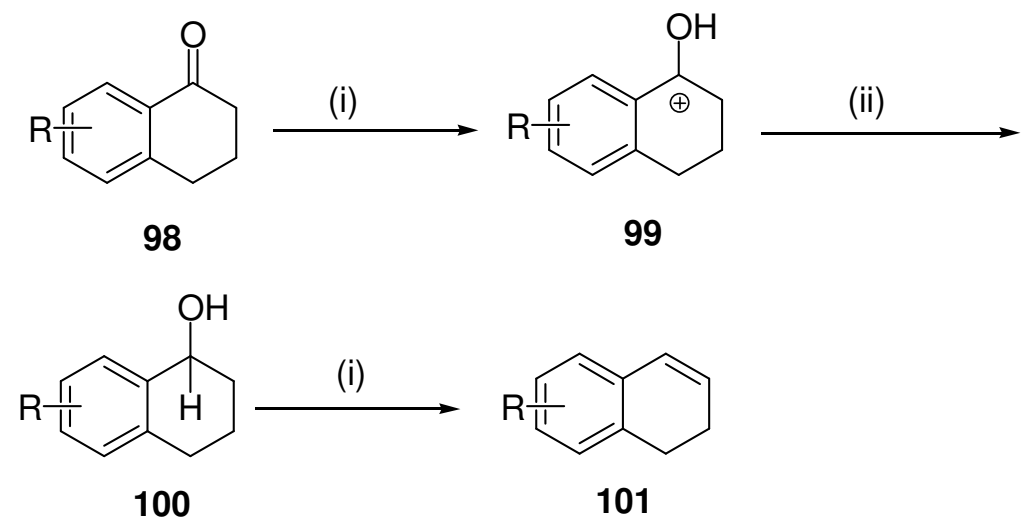

Reagents:(i) PTSA, Toluene, reflux; (ii) 2,4-pentanediol

\section{Scheme 20}




\section{Conclusions}

The present review summarizes the results of our investigation concerning the transformation of carbonyl compounds, mostly decalones and tetralones, into the alkenes using several reagents. The resulting olefinic compounds were utilized for the synthesis of natural products and bioactive compounds. We have shown the importance of several reagents in the conversion of carbonyl compound into the alkene. We hope in near future more reagents will be utilized for the transformation of the carbonyl group into the alkene.

\section{References}

1. Banerjee, A. K.; Caraballo, P. C. Ind. J. Chem. 1983, 22B, 1259.

2. Miller, R. B.; Nash, R. D. J. Org. Chem. 1973, 38, 4424. http://dx.doi.org/10.1021/jo00965a015

3. Banerjee, A. K.; Caraballo, P. C. J. Chem. Res. 1984, 284.

4. Torii, S.; Inokuchi, T. B. Chem. Soc. Jpn. 1980, 53, 2642. http://dx.doi.org/10.1246/bcsj.53.2642

5. Endo, K.; Hikino, H. B. Chem. Soc. Jpn. 1979, 52, 2439. http://dx.doi.org/10.1246/bcsj.52.2439

6. Shiozaki, M.; Mori, K.; Matsui, M. Agric. Biol. Chem. 1972, 36, 2539. http://dx.doi.org/10.1271/bbb1961.36.2539

7. Chetty, G. L.; Rao, G. S. K.; Dev. S.; Banerjee, D. K. Tetrahedron 1966, 22, 2311. http://dx.doi.org/10.1016/S0040-4020(01)82151-7

8. Wolinsky, J.; Lau, R.; Hamsher, J.J.; Cimarusti, C. M. Synthetic Commun. 1972, 2, 327. http://dx.doi.org/10.1080/00397917208061989

9. Olah, G. A.; Husain, A.; Gupta, B. G.; Narang, S.C. Angew. Chem. Int. Ed. 1981, 20, 690. http://dx.doi.org/10.1002/anie.198106901

10. Banerjee, A. K.; Azocar, J. A. Synthetic Commun. 1999, 29, 249. http://dx.doi.org/10.1080/00397919908085764

11. Garver, L. C.; Van Tamelen, E. E. J. Am. Chem. Soc. 1982, 104, 867. http://dx.doi.org/10.1021/ja00367a046

12. Dauben, W. G.; Ashcraft, A. C. J. Am. Chem. Soc. 1963, 85, 3673. http://dx.doi.org/10.1021/ja00905a032

13. Santaniello, E.; Ponti, F.; Manzocchi, A. Synthesis 1978, 891. http://dx.doi.org/10.1055/s-1978-24927

14. Frater, G. J. Chem. Soc., Chem. Commun. 1982, 521.

15. Banerjee, A. K.; Pena-Matheud, C. A.; Carrasco, M. C. J. Chem. Soc., Perkin Trans I 1988, 2485. 
16. Banerjee, A. K.; Canudas-Gonzalez, N.; Cabrera-Nieto, G.; Pena-Matheud, C. A. J. Chem. Res (S) 1990, 266.

17. Banerjee, A. K.; Azocar, J. A. Monatshefte fur Chemie 1996, 127,1031. http://dx.doi.org/10.1007/BF00807575

18. Rudloff, E. V.; Erdtman, H. Tetrahedron 1962, 18, 1315. http://dx.doi.org/10.1016/0040-4020(62)80012-X

19. Banerjee, A. K.; Correa, J. A.; Laya, M. S. J. Chem. Res (S) 1998, 710.

20. Sondheimer, F.; Elad, D. J. Am. Chem. Soc. 1957, 79, 5542. http://dx.doi.org/10.1021/ja01577a057

21. Aasen, A. J.; Vogt, C. H. G.; Enzell, C. R. Acta. Chem. Scand. Ser. B 1975, 29, 51. http://dx.doi.org/10.3891/acta.chem.scand.29b-0051

22. Roberts, J. D.; Young, W. G.; Winstein, S. J. Am. Chem. Soc. 1942, 64, 2157. http://dx.doi.org/10.1021/ja01261a041

23. Darzens, G. C. R. Acad. Sci. 1911, 152, 1601.

24. Banerjee, A. K.; Canudas-Gonzalez, N.; Sepulveda, M. C. J. Chem. Res (S) 1992, 310.

25. ApSimon, J. W.; Yamasaki, K. Chem. Lett. 1977, 1453.

26. Banerjee, A. K.; Vera, W. Rec. Trav. Chim. Pays B. 1995, 114, 87. http://dx.doi.org/10.1002/recl.19951140303

27. Banerjee, A. K.; Hurtado, H. E.; Carrasco, M. C. Synthetic Commun. 1980, 261. http://dx.doi.org/10.1080/00397918008062748

28. Banerjee, A. K.; Hurtado, H. E.; Carrasco, M. C. J. Chem. Soc., Perkin Trans I 1982, 2547.

29. Banerjee, A. K.; Carrasco, M. C. Synthetic Commun. 1983, 13, 281. http://dx.doi.org/10.1080/00397918308066977

30. Matsumoto, T.; Usi, S.; Morimoto, T. B. Chem. Soc. Jpn. 1977, 50, 1575 and references cited there in.

31. Banerjee, A. K.; Laya, M. Monatshefte fur Chemie 1997, 128, 1255. http://dx.doi.org/10.1007/BF00807257

32. Banerjee, A. K.; Azocar, J. A.; Vera, W. Synthetic Commun. 1999, 29, 2995. http://dx.doi.org/10.1080/00397919908086474

33. Bohlmann, F.; Eickeler, E. Chem. Ber. 1979, 112, 2811.

http://dx.doi.org/10.1002/cber.19791120807

34. Banerjee, A. K.; Rizo, M. S.; Alonso, M. E.; Rojas, A.; Haack, J. L.; House, H. O.; Vanderveer, D. J. Org. Chem. 1981, 46, 1755.

http://dx.doi.org/10.1021/jo00321a054

35. Banerjee, A. K.; Carrasco, M. C.; Pena-Matheud, C. A. Rec. Trav. Chim. Pays. B. 1989, 108, 94. http://dx.doi.org/10.1002/recl.19891080303

36. Banerjee, A. K.; Castillo-Melendez, J. A.; Vera, W.; Azocar, J. A.; Laya, M. S. J. Chem. Res. (S) 2000, 324. 
37. Banerjee, A. K.; Pineda, J. R.; Mora, H. D.; Laya, M. S. Synthetic Commun. 2007, 37, 3917. http://dx.doi.org/10.1080/00397910701572431

38. Negishi, E.; Idacavage, M. J. Tetrahedron Lett. 1979, 845. http://dx.doi.org/10.1016/S0040-4039(01)93567-1

39. Martin, R. H.; Robinson, R. J. Chem. Soc. 1943, 491. http://dx.doi.org/10.1039/jr9430000491

40. Paul, T.; Mukerjee, D. Tetrahedron Lett. 2003, 44, 4985. http://dx.doi.org/10.1016/S0040-4039(03)01170-5

41. Vera, W. J.; Banerjee, A. K. J. Chem. Res (S) 2006, 707.

42. Poon, P. S.; Banerjee, A. K. Synthetic Commun. 2008, 38, 2261. http://dx.doi.org/10.1080/00397910802026204

43. Banerjee, A. K.; Melean, C. E.; Mora, H. D.; Cabrera, E. V.; Laya, M. S. J. Chem. Res (S) 2007, 117.

44. Garofalo, A. W.; Litvak, J.; Wang, L.; Dubenko, L, G.; Copper, R.; Bierer, D. E. J. Org. Chem. 1999, 64, 3369.

http://dx.doi.org/10.1021/jo9822838

PMid:11674448

45. Banerjee, A. K.; Poon, P. S. Arkivoc 2009, (xiii), 108.

46. Vuligonda, V.; Lin, Y.; Chandraratna, R. A. S. Tetrahedron Lett. 1996, 37, 1941. http://dx.doi.org/10.1016/0040-4039(96)00309-7

47. Banerjee, A. K.; Vera, W.; Laya, M. S. Synthetic Commun. 2004, 34, 2301. http://dx.doi.org/10.1081/SCC-120038516

48. Vera, W.; Banerjee, A. K. Arkivoc 2009, (xi), 228. http://dx.doi.org/10.3998/ark.5550190.0010.b20

49. Cabrera, E. V.; Sánchez, J. L.; Banerjee, A. K. Org. Prep. Proc. Int. 2011, 43, 364. http://dx.doi.org/10.1080/00304948.2011.594008

50. Vera, W.; Banerjee, A. K. Synthetic Commun. 2006, 36, 3091. http://dx.doi.org/10.1080/00397910600775663

51. Banerjee, A. K.; Vera, W. J. Chem. Res (S) 2004, 135. 


\section{Author's Biography}

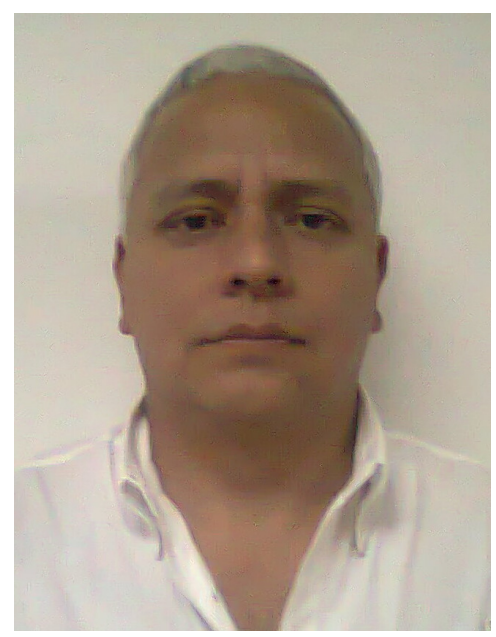

William J. Vera, who obtained M.Sc degree from IVIC, is working as a research associate in the department of chemistry of Venezuelan Institute of Scientific Research (IVIC), Caracas, Venezuela. His published works are related to the synthesis of terpenoid and heterocyclic compounds. At present, his research interests are the synthesis of organic compounds using microwave irradiation and synthetic studies on terpenoid compounds.

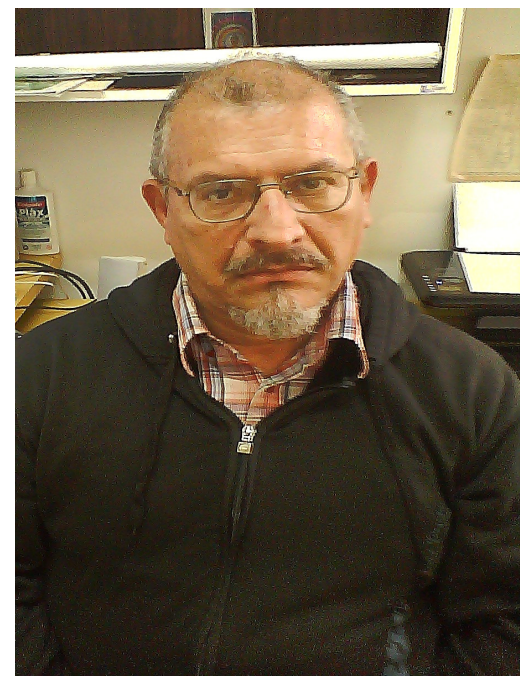

Manuel S. Laya, who obtained M.Sc degree in 1997 from IVIC, is working as research associate in the department of chemistry, IVIC. He has published several papers most of which are related to synthetic studies on terpenoid compounds. 


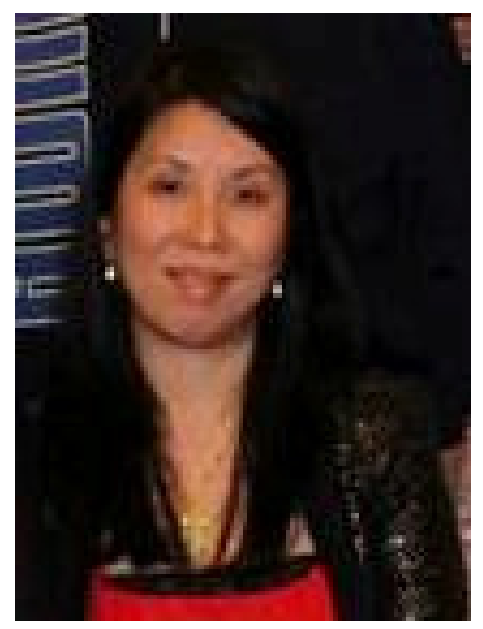

Po S. Poon is an associate investigator in the Chemistry department at Venezuelan Institute of Scientific Research (IVIC). Dr. Poon obtained his B.S. degree in chemistry from the University of Carabobo, Venezuela. In 2007, Dr. Poon received his Ph. D. in organic chemistry at IVIC. She did a short postdoctoral training in the Department of Organic Chemistry at University of Valencia, Spain in 2011. Her research interests include design and synthesis of bioactive compounds, and development of new synthetic methods based on green chemistry.

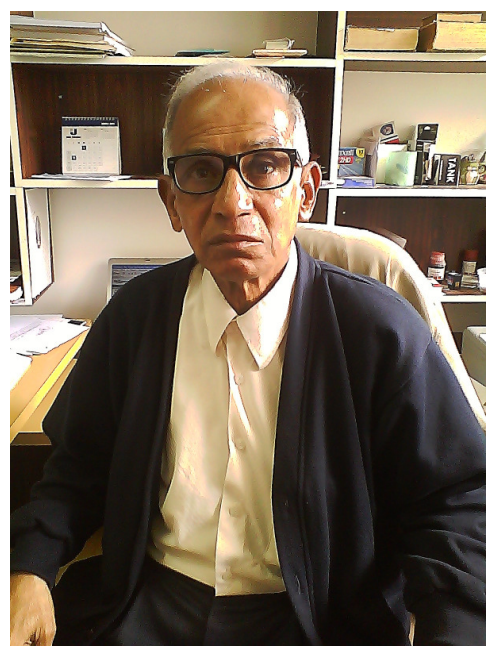

Ajoy K. Banerjee, who received D.Phil degree 1965 from the University of Kolkata (India), joined at IVIC in 1968. Since 1982 till now he is working as senior research scientist. Most of his works are related to synthetic studies on terpenoid compounds (diterpenes and sesquitepenes). He teaches organic chemistry (mainly reaction mechanism and molecular rearrangements) to the students who join IVIC for M.Sc or Ph.D degree. Dr. Banerjee is the author of two books on organic chemistry written in Spanish language. 


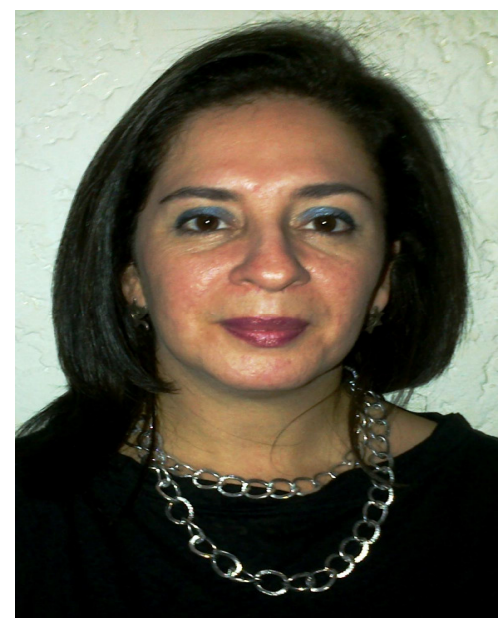

Elvia V. Cabrera is associate professor of organic chemistry at the University of Zulia, Maracaibo, Venezuela. In 2012, Dr. Cabrera received her Ph. D. in organic chemistry from University of Zulia. Her research work is related to the synthesis of natural products related to sesquiterpenes. 